\title{
La crisis económica del Ecuador 1999-2000
}

The economic crisis of Ecuador 1999-2000

Vera Baque Johnny Adrian ${ }^{1}$,

DOI: https://doi.org/10.33262/visionariodigital.v1i4.254

\section{Resumen.}

En si el Ecuador ha sufrido una serie de trastornos y embates de distinto orden que se han confabulado para impedir el progreso y desarrollo del país, con la consecuente sobre el Sistema Financiero y por tal en el sector productivo. El proceso de reactivación de la economía ecuatoriana se detiene súbitamente en 1995, pues sobrevino una cadena de desestabilizadores externos e internos que sacaron a la luz graves falencias tanto estatales como privadas.

Los administradores de los bancos quebrados, autoridades y funcionarios encargados de vigilar los negocios bancarios que fueron cómplices, no han recibido la sanción penal correspondiente por su actuar doloso, y ello refleja la poca eficiencia, moralidad y eficacia en la administración del Estado. Como siempre el Estado siempre termina perdiendo, y como consecuencia la población ecuatoriana.

Palabras clave: Sistemas, financiero, funcionarios.

\begin{abstract}
.
If Ecuador has suffered a series of disorders and attacks of different order that have conspired to prevent the progress and development of the country, with the consequent on the financial system and for that in the productive sector. The process of reactivation of the
\end{abstract}

1 Vera Baque Johnny Adrian Ecuador 
Ecuadorian economy stops suddenly in 1995, as a chain of external and internal destabilizes came to light that brought to light serious flaws both state and private.

The administrators of the bankrupt banks, authorities and officials in charge of supervising the banking businesses that were accomplices, have not received the corresponding penal sanction for their fraudulent actions, and this reflects the low efficiency, morality and efficiency in the administration of the State. As always, the State always ends up losing, and as a consequence the Ecuadorian population.

Keywords: Systems, financial, officials

\section{Introducción.}

Wilson Fernando Palomeque León., Obando, I. A., (Eduardo Cerdas, 2006)

La crisis que enfrentó el país a fines de 1995 y durante 1996 afectó fuertemente al sistema financiero como consecuencia de la contracción de su actividad sobre todo la crediticia. La banda cambiaria se ajustó dos veces a lo largo del año 1995 y una en 1996 en el mes de Agosto , lo cual ocasionó que la tasa básica del Banco Central registre gradualmente un descenso, al disminuir del $46.3 \%$ en Julio de 1996 al 19.2\% en Diciembre del mismo año

En los últimos días se ha presentado de una manera muy fuerte la noticia de que en el Ecuador tendremos un problema muy grave en materia económica que afectara al país, parece mentira el pensar que recién nos estamos dando cuenta y admitiendo que esto si iba a pasar, hace mucho se ha advertido que al país se le presentaría una crisis económica para considerar rectificaciones que disminuya los efectos de este mal económico.

Indicadores como la baja de los precios del petróleo, la disminución de los envíos de remesas por parte de los migrantes, además de decisiones gubernamentales como el de crear un número innecesario y exagerado de ministerios, realizar un excedido número de viajes al extranjero, gasto electoral en campaña política con dinero estatal, y además de 444 millones de dólares en una constitución para el Ecuador, son solamente algunas de las razones de la falta de recursos económicos que traerán esa crisis económica que ha afectado ya en gran parte a la economía mundial.

En este año el país dejará de percibir unos 9.000 millones de dólares, por la baja en el precio del crudo, hasta 800 millones por las remesas de los emigrantes y más de 1.500 millones, debido a la caída de las exportaciones no petroleras. 


\section{VDD Digitital}

ISSN 2602-8506

Vol. 1 / No.4/ pág. 5-20. Octubre-Diciembre/2017

Nos encontramos, por lo tanto, rodeados de esta gran enfermedad económica que acoge al Ecuador, ahora nos encontramos hundidos en los problemas que traerán esta crisis económica, de la cual los afectados, y los que tendrán que sufrir las consecuencias, seremos los habitantes del país, quienes tendremos que vivir una inseguridad, como la ya vivida en épocas y gobiernos anteriores, en el que los Ecuatorianos se preguntaban ¿Cómo resistir a la falta de recursos económicos?, esta es la dureza que se nos presenta en nuestra actualidad.

El siglo XX traía una banca nacional en una etapa media de crecimiento, sin embargo, al fin de este siglo, la banca nacional se encuentra técnicamente quebrada. En este momento varias instituciones financieras, entre Bancos y sociedades financieras han sufrido una quiebra, se hallan en saneamiento o reestructuración (status jurídico creado por la Ley de Reordenamiento en Materia Económica en el Área Tributario Financiero del 1 de diciembre de 1998), que en la actualidad ya no rige. Dichas instituciones en su mayoría se hallan cerradas por causa de una mala o dolosa administración

\section{¿Qué ocurrió en la economía?}

Las medidas tomadas durante la crisis produjo resultados, aunque lentos, en la reactivación del crecimiento económico a partir de 2001. El crecimiento del PIB de Ecuador mejoró

Sustancialmente de $-6,3 \%$ en 1999 a 3,2\% en 2005 y la inflación bajó desde $29,2 \%$ a 4\% en el mismo período. Sin embargo, la recuperación post-dolarización fue en parte resultado del alza en los precios del petróleo y las remesas de los emigrantes.

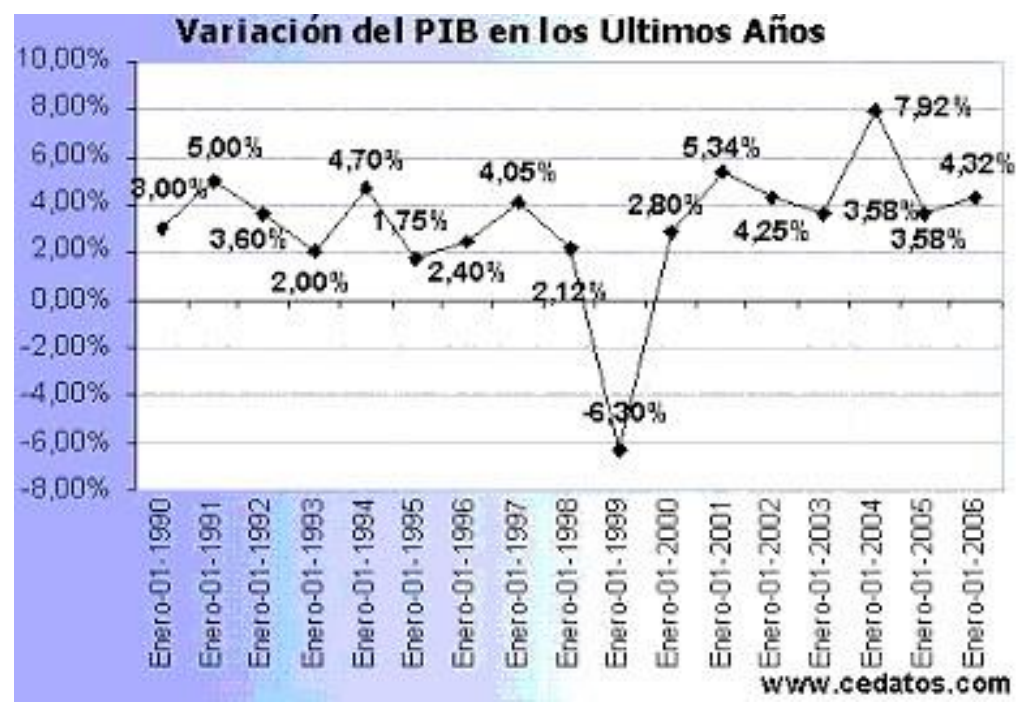


Por su parte, la demanda interna disminuye sobre el 10\%. Como resultado de esta situación el desempleo y el subempleo suben, en el último año, al $16 \%$ y $57 \%$, respectivamente, lo que pone en evidencia que alrededor del $75 \%$ no tienen pleno empleo y que más de los $2 / 3$ de la población se encuentra en situación de pobreza.

Con respecto de los indicadores macro económicos el déficit fiscal que era de $-1.5 \%$ respecto del PIB aumenta hasta $-5.8 \%$. No obstante, el pago de los intereses de la deuda pública

(interna y externa) se incrementan al 7\% del PIB. Si al pago de intereses agregamos la amortización de la deuda pública, las necesidades brutas de financiamiento fueron de casi el $11.8 \%$ del PIB en 1998 y 11\% en 1999. De otra parte, el servicio de la deuda pública total (externa e interna) de alrededor de 16.000 millones de dólares, se aproxima al 50\% de las exportaciones de bienes y servicios no factoriales.

Ante la amenaza de hiperinflación y otros problemas generados por la inestabilidad y especulación, el gobierno de Mahuad adoptó la dolarización de la economía oficialmente a

inicios del 2000. La medida, sin embargo, no logró evitar la caída de este régimen político, empero el siguiente gobierno respaldó la dolarización, delineando una estrategia de

Estabilización e incipiente recuperación económica que se ha mantenido hasta el presente.

Los gobiernos de Noboa (2000-2002) y Gutiérrez (2003-2005) han buscado estabilizar en el corto plazo la economía a través de la dolarización, y consolidar la recuperación mediante la promoción de la inversión extranjera en el sector petrolero, encaminada a la construcción de un nuevo oleoducto y la casi duplicación de los volúmenes exportados en el plazo de dos años.

Las políticas fiscales han buscado aumentar las recaudaciones mediante una mayor eficiencia tributaria, la eliminación del subsidio al gas (no adoptada aún), la elevación de los precios de la electricidad y los combustibles, y cambios en la estructura tributaria (tampoco implementados en su totalidad). La austeridad fiscal y la conformación de un fondo de estabilización para el pago y la recompra de la deuda externa, con los ingresos petroleros, han buscado reducir el peso de la deuda en el mediano plazo y estabilizar la economía. 
En resumen, se esperaba que la afluencia de divisas del petróleo, la austeridad fiscal, y la reducción de la inflación y las tasas de interés bajo la dolarización crearan un ambiente de

Estabilidad y confianza que favoreciera la inversión privada y la reactivación de la economía.

\section{La baja de precio del petróleo}

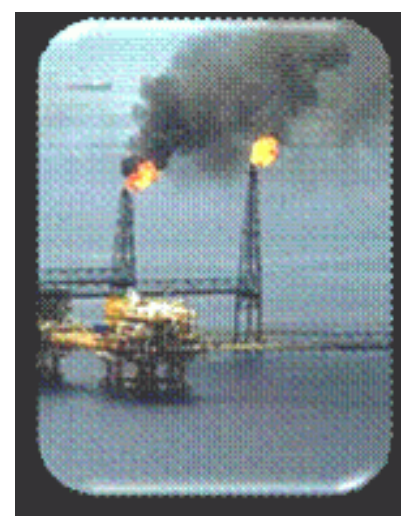

El precio del petróleo, es fijado en base al marcador estadounidense West Texas Intermédiate (WTI) cuyo diferencial es establecido mensualmente por Petroecuador. WTI: es la mezcla de petróleo crudo ligero que se cotiza en el New York Mercantiles Exchange y sirve de referencia en los mercados de Petro-derivados de los EE.UU.

La espectacular subida del precio del barril de petróleo en el mercado mundial experimentada hasta julio del presente año, cuando se cotizó sobre los 134.71 el West Texas Intermédiate, WTI, de Estados Unidos; comparada con la dramática caída que llevó a cotizarlo el pasado viernes hasta en 61.04 dólares en el New York Mercantiles Exchange el barril de WTI, es una muestra de la "volatilidad" del mercado petrolero mundial, cuya variación de precios incide en los movimientos económicos y en las finanzas de los países del mundo.

Ecuador, como país petrolero, cuyo presupuesto para el 2009 está condicionado en un 49 por ciento por las rentas petroleras, no está libre de las turbulencias y volatilidad del mercado petrolero, lo cual obligará a tomar medidas previsoras para por un lado poder continuar con los programas y proyectos emprendidos, y por otro, sincerar las cifras con la realidad de los ingresos condicionados por el mercado del crudo. 
Vol. 1 / No.4/ pág. 5-20. Octubre-Diciembre/2017

Esta fatal caída de los precios de nuestro petróleo hace mas difíciles los esfuerzos por continuar con la obra pública que permite la creación de empleos, estimular el comercio y dinamizar la economía en general, debe ser una prioridad del país, se debe pensar en la insustituible necesidad de inversión en gasto social, destinado a la salud pública y educación.

Po su parte, el Gobierno Nacional resolvió pedir a la Organización de Países Exportadores de Petróleo, OPEP, respetar la cuota preferencial de 493.000 barriles diarios de petróleo para que el Ecuador no se incorpore una nueva reducción, luego de que la organización dispuso en octubre pasado bajar su producción en 1.500 .000 barriles para enfrentar la caída del precio del crudo.

Sin embargo e independientemente, el precio del crudo se mantendrá entre los 50 y 80 dólares en los próximos meses, según varios analistas en el tema petrolero, su previsión está por debajo de los 85,4 dólares, cifra que se incluyó en la pro forma presupuestaria de 2009.

Ha existido en el precio del petróleo ecuatoriano, un ligero repunte, después de que el siete de noviembre de 2008, el barril estuvo en 44,87 dólares. Esta cifra incluye los descuentos que recibe el crudo por su mala calidad. El hidrocarburo a nivel mundial se cotizó en 61 dólares.

Existen tres factores que pueden influir en el costo del barril de petróleo. El primero depende del comportamiento de la economía estadounidense ante la crisis financiera. El segundo de cómo los norteamericanos enfrenten el invierno. Se espera que en los meses de noviembre, diciembre y enero aumente el uso de combustibles en calefacción para contrarrestar los efectos de las bajas temperaturas. El último depende de la reacción de la Organización de Países Exportadores de Petróleo, OPEP. De acuerdo a las políticas que formule esta institución el precio puede estar al alza en el mediano plazo.

La caída de la actividad económica a nivel mundial muestra un escenario poco favorable para tener un barril de petróleo a 100 dólares. A esto se suma que Ecuador es socio de la OPEP y este organismo tiene en planes recortar la producción petrolera; sin embargo, la Agencia Internacional de Energía, AIE, proyectó que los precios del petróleo se mantendrán en los próximos años por encima de los 100 dólares, según la revista especializada Petroleum World. 


\section{VDDDigital}

ISSN 2602-8506

Vol. 1 / No.4/ pág. 5-20. Octubre-Diciembre/2017

El Ecuador, debería considerar el tema petrolero como prioritario, no tanto en materia de precios y de cuotas de producción; sino más bien, en el sentido de dejar de depender exclusivamente de esta fuente de ingresos que dicho sea de paso es agotable y no renovable. Es hora de mirar hacia otras alternativas que permitan un desarrollo sustentable de nuestro país, lo cual permitirá dinamizar la economía y dejar de ser dependientes de este recurso que no durará mucho; a demás ya los países desarrollados están buscando nuevas fuentes energéticas que sustituyan en gran medida al petróleo. Por lo tanto debemos plantearnos en forma oportuna y responsable esta realidad que cada vez se hace más evidente, y que en lugar de propender al crecimiento y desarrollo nacional, ha sumido a la patria en el subdesarrollo.

\section{Disminución de los envíos de dinero de los migrantes}

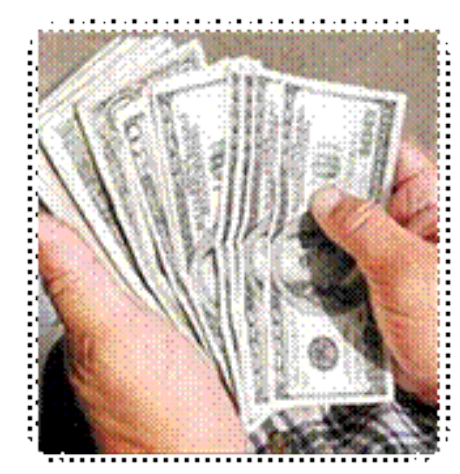

Las remesas son importantes en la economía ecuatoriana, pues constituyen el segundo rubro de ingresos después del petróleo, más aún, en la economía no petrolera del país, se puede prever que las remesas sigan siendo muy importantes. Las remesas también rebasan la inversión privada que se realizan en el país y los recursos que llegan bajo el concepto de cooperación al desarrollo. Pero además, constituyen el capital que más se democratiza y socializa en el Ecuador, al llegar en forma directa a alrededor de un millón de familias, la mayoría de ellas de clase media y media baja. Sin embargo, en el análisis se hace necesario ir más allá de las remesas y evitar caer en el endiosamiento de estos recursos económicos que envían los ecuatorianos desde el exterior.

Las remesas enviados por los trabajadores migrantes de América Latina y el Caribe caerán abruptamente en el 2009. Ya comenzaron a frenarse en el 2008 tras una década de crecimiento, según un estudio del Banco Interamericano de Desarrollo BID; y fue acentuándose este decrecimiento a medida que países como los EE.UU., España y Japón, 


\section{VDD Digital}

ISSN 2602-8506

Vol. 1 / No.4/ pág. 5-20. Octubre-Diciembre/2017

entraban en recesión. Nuestro país está entre otros países de Latinoamérica que reciben dinero de España y se beneficiaron de la fortaleza del euro durante el primer semestre de 2008 pero más tarde han sido afectados por la caída de la moneda europea. El Ecuador ha sido el más afectado, de acuerdo con el BID, ya que cuenta con una economía dolarizada y una gran población en España, que ha sido azotada por el desempleo y la depreciación del euro. Las remesas, que en un $47 \%$ llegan desde EE.UU. y $41 \%$ desde España (dato de la CAN), se redujeron en un 22\%. Según los últimos datos publicados por el Fondo Monetario Internacional, e Instituciones financieras como el Banco de España y recogidos por la prensa europea. Se trata de la primera caída en envíos en estos últimos años de alta afluencia de inmigrantes, y Ecuador está en la lista de los países que podrían verse como más perturbados por este problema.

Los datos de la autoridad monetaria española ponen de manifiesto el impacto de la crisis económica y del incremento del desempleo entre la población extranjera, que aumentó un $5,2 \%$ en el mes de febrero, además del cambio de signo en la evolución de las tendencias podría hacerse más pronunciado en 2009 , dado que todas las previsiones apuntan a que la desaceleración económica desincentivará el viaje de migrantes a países como España y Estados Unidos.

Nuestro país consta entre los países que reciben más remesas desde España y cuyas economías pueden verse más afectadas. Ecuador, que recibe de España el $40 \%$ de sus remesas, vio descender los envíos totales en un 8,6\% en 2008, la situación de los ecuatorianos, que suman aproximadamente 460.000 legales y 150.000 indocumentados, es cada vez más crítica, sobre todo para los que laboran en el sector de la construcción.

El desempleo entre los compatriotas se incrementa cada vez más, por lo que los inmigrantes no tienen dinero para enviar a sus familiares y prevé que para finales de 2009 la situación empeorará. Actualmente hay cerca de 50.000 compatriotas desocupados.

"Las remesadoras ahora lucen vacías, no como antes que se veían largas colas; y de acuerdo con datos de Observatorio de la Política Fiscal de Ecuador, de los 3.000 millones de dólares que ingresaron al país por las remesas en 2008, el $40 \%$ provino de España, es decir 1.200 millones de dólares. Sin embargo, se prevé que esta cifra disminuya en un $20 \%$ a finales de 2009. 


\section{VDDDigital}

ISSN 2602-8506

Vol. 1 / No.4/ pág. 5-20. Octubre-Diciembre/2017

Las remesas nos vuelven a la realidad del aporte migrante al desarrollo del país y al de las familias que invierten los montos recibidos. Hay que tomar en cuenta que las remesas son la única fuente de supervivencia para un gran número de familias de escasos y medianos recursos en los países de emigración, y por supuesto en Ecuador, que se emplean mayoritariamente en satisfacer las necesidades básicas de salud, educación, recreación, vestido y vivienda, es decir en desarrollo.

Según serios analistas se estima que las remesas disminuirán en el 2009 y en referencia al 2008, entre un 15 y 30 por ciento, lo que significaría una reducción entre 500 y 1000 millones de dólares sobre un monto total de remesas aproximado de 3.300 millones de dólares. La Comunidad Andina de Naciones, más modesta, calcula para Ecuador en el 2009 un monto de remesas llegadas de unos 2.800 millones de dólares.

\section{Prohibición de importaciones}

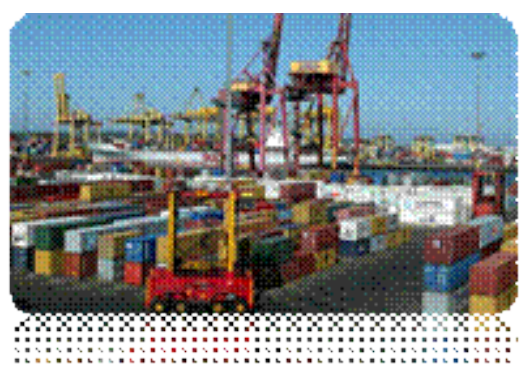

El gobierno del Ecuador adoptó la restricción de importaciones, como medida para hacer frente a la crisis financiera internacional, esta recayó en 647 subpartidas, el 8,5 por ciento del total. Según los analistas, esta reducción pretende reducir el costo de las importaciones en unos 1.459 millones de dólares respecto al monto de 2008.

La resolución señaló que la medida tiene carácter temporal por un año y que es "de aplicación general, no discriminatoria, de las importaciones de todos los países del mundo, incluyendo aquellos con los que Ecuador tiene acuerdos comerciales vigentes que reconocen preferencias arancelarias".

Algunos de los productos afectados con mayor recargo, de un $35 \%$ en su valor, son las bebidas alcohólicas, los productos electrónicos, como teléfonos móviles o reproductores de música y películas y los muebles, entre otros. 
Partidas importadas de juguetes y videojuegos, maquillaje, bombones, pastas o mermelada, entre otros, fueron grabadas con un $30 \%$ de recargo.

Además, el calzado sufrió un recargo de 10 dólares por par importado, y los productos del sector textil un recargo de 12 dólares por kilo.

Según la visión estrecha del proteccionismo es beneficioso defender a determinados sectores contra las importaciones. Pero esa percepción no tiene en cuenta la reacción de sus socios comerciales. A muy corto plazo, en realidad, hemos visto que esta medida proteccionista ha empezado a suscitar represalias por parte de otros países, provocando la pérdida de confianza en la liberación del comercio.

Todas las decisiones en cuanto a las políticas de comercio exterior de los países, traen como consecuencia una respuesta del resto de la comunidad comercial internacional; en especial si se trata de crear barreras proteccionistas a las importaciones, tales como restricciones y aumento en los aranceles.

Con relación a la Industria nacional, esta medida trató de favorece a fortalecer este sector de la economía, debido a que al restringir las importaciones, el consumidor nacional se ha visto encausado de alguna manera a consumir los productos nacionales, ya que los equivalentes importados han aumentado sustancialmente en sus precios. De tal manera que la industria local eventualmente ha elevado sus ventas. Con esta medida se trató de "cambiar una estructura de consumo que privilegiaba lo importado".

Al fortalecerse la industria nacional con la restricción de las importaciones o el alza de los aranceles a las mismas, se pretendía favorecer a la inversión y por ende al aumento de las fuentes de trabajo para los ecuatorianos. Al mismo tiempo se generaría un incremento en sus utilidades, y por lo tanto y al menos en teoría habría un auge de la industria nacional; a demás, el Estado se constituiría en uno de los beneficiarios de esta medida porque las arcas fiscales experimentarían un aumento de sus ingresos por este concepto. Pero habiendo transcurrido ya varios meses; debemos hacer un balance de los efectos conseguidos, y es así que vemos como a través de otras políticas implementadas en el ámbito laboral y tributario no se ha dado el apoyo a la empresa ni se ha generado un clima de confianza en los inversionistas. Esperemos por el bien de nuestro país que a largo plazo esta medida vaya en beneficio del pueblo y no de ciertos grupos económicos. 


\section{VD Digitital}

ISSN 2602-8506

Vol. 1 / No.4/ pág. 5-20. Octubre-Diciembre/2017

No debemos dejar de lado el hecho de que el dinero que ahora pagamos por un producto nuestro, queda en nuestro país y se evita la salida de las divisas hacia el exterior, reconociendo que hoy por hoy, la industria nacional es muy competitiva en la mayoría de productos, no olvidemos que muchos productores nacionales realizaron inversiones en miras al tratado de libre comercio; y consideremos que al elegir lo nuestro, el consumidor no se ha visto afectado en el aspecto de calidad.

En lo que corresponde al Ecuador, las primeras reacciones de países con los que el Ecuador negocia, no se hicieron esperar; tal es el caso de Argentina que detuvo el ingreso de productos ecuatorianos hasta fijar nuevos aranceles para los mismos; Perú está pidiendo una reconsideración para sus productos que exporta a Ecuador, y, Colombia ha prohibido el ingreso de productos avícolas de origen ecuatoriano. Existen países que ya empiezan a hacer escuchar su voz, y eso nos debe poner en alerta para seguir corrigiendo al paso lo que se pueda y necesite, de tal manera que al termino de este año, veamos un mejor futuro para todos.

\section{Alza de precios de todos los productos}

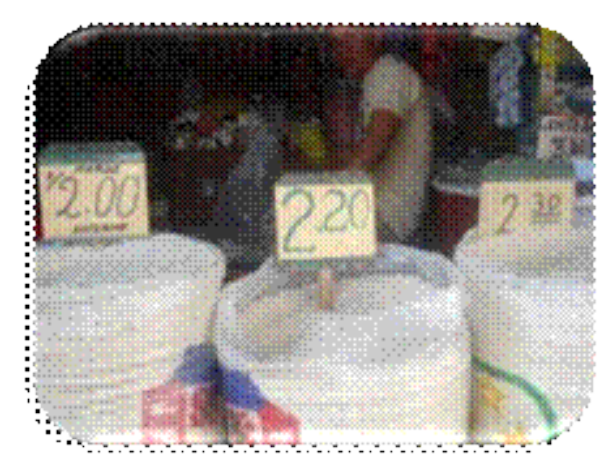

La elevación del precio en todos los productos es algo que no pasa inadvertido al habitante de este país, sino que, más bien confirma el hecho de que el Ecuador siente ya el golpe de la crisis que afecta al mundo entero.

En todos los órdenes y en todas las escalas, hay un aumento a veces drástico e inexplicable de los precios, partiendo de los productos de primera necesidad que en el transcurso de una semana se ven afectados en porcentajes de alza de hasta el $200 \%$, todos los sectores han sido golpeados. 


\section{VDDDigital}

ISSN 2602-8506

Vol. 1 / No.4/ pág. 5-20. Octubre-Diciembre/2017

La inflación que en el año 2008 bordeó el 8,3 \% se repetirá este año, con la agravante de que existe menos circulante y que esto provocará un descenso dramático en las ventas, provocando una paralización al comercio y por ende a la industria.

Las fluctuaciones en el precio del petróleo, la disminución en las remesas que vienen del exterior, las medidas cautelares en el sector importador, todo se ha confabulado para ahondar esta crisis e influir directamente en los precios y por ende en la economía familiar de los ecuatorianos; de tal manera que nuestra economía dolarizada ha entrado en una carrera inflacionaria que es necesario detenerla. Se ha hablado de que es necesario pensar en una moneda sustitutiva del dólar, pero debemos analizar en que beneficiaría eso a la micro economía, ya que al pasar a otra moneda de curso legal nos rondaría el fantasma de la devaluación para nuevamente volver a como estuvimos antes de la adopción del dólar como moneda oficial.

Pero no todo es negativo, hay aspectos que pueden considerarse "positivos" dentro de el contexto sobre todo internacional, específicamente en el área agrícola, debido a que productos como el arroz, maíz, avena y trigo, los granos básicos de la dieta mundial han subido de precio en el último año entre un 80 y 100\%. Esto producido por la sobre demanda de China e India, sequías, problemas políticos en países por todo el mundo, etc. Esto ha traído preocupación en gobiernos y agencias a nivel mundial. En nuestro propio país, el Presidente dice a los maiceros que se vienen tiempos difíciles; sin embargo si este problema se toma como una oportunidad, es factible deducir que por la extensión de tierras no cultivadas en el agro, si estas la destinamos a la obtención de estos productos, nos beneficiaríamos de las exportaciones de los mismos, convirtiendo al Ecuador en un verdadero granero de América Latina.

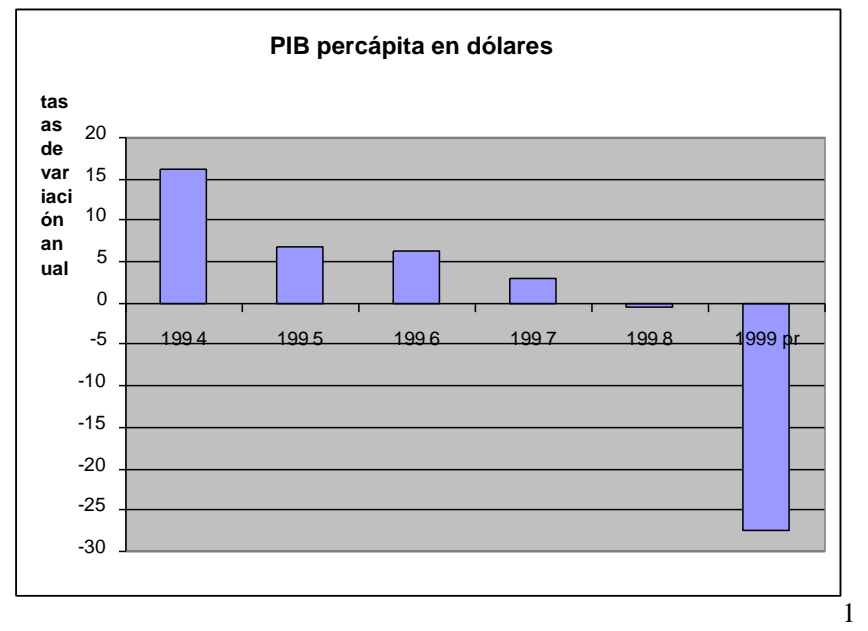


Fuente: Toda la información económica, salvo que se indique lo contrario, proviene del Banco Central del Ecuador. INFORMACION ESTADISTICA MENSUAL, N- 1765 Y 1766, Marzo 31 y Abril 30 de 1999, WWW.BCE.FIN.EC

${ }^{1}$ Ver CEPAL. Balance preliminar de la economía de América Latina y El Caribe, 1998, Resumen, www.cepal.org

\section{Después de la crisis.}

El nuevo esquema económico trajo consecuencias tanto negativas como positivas. Por una lado se beneficiaron ciertos grupos reducidos de ecuatorianos, que ostentan el capital económico del país, pero que sin embargo, no aportan considerablemente a la redistribución equitativa de la riqueza.

- El sistema financiero se beneficio del cobro de comisiones por la mayoría de sus servicios.

- Los importadores que se benefician de una moneda que no les representa cambios impredecibles y con la que obtienen mejores precios en países que si devalúan su moneda.

- El sector de la construcción que se ha favorecido del auge consumista que ha caracterizado a los agentes económicos en los últimos años, producto de su preferencia por la liquidez antes que el ahorro en bancos.

- Los servicios de telefonía móvil ahora son de más fácil acceso para la población ya que antes de la dolarización resultaban restrictivos para la gran mayoría.

- El gobierno central que ha visto incrementar su recaudación tributaria pues el monto que ahora recauda no se devalúa con el tiempo.

Entre los principales sectores a los que la medida los ha perjudicado se tienen:

- Los productores y exportadores que al no contar más con el beneficio de la devaluación están obligados a ser eficientes y creativos para competir con productos similares y a menores precios, toda vez que la competencia si cuenta con una moneda adaptable a las necesidades de su comercio exterior.

- Los asalariados y en relación de dependencia teniendo presente que el salario unificado es de apenas \$160 lo que no compensa el elevado costo de vida en Ecuador. 
- La pequeña y mediana empresa al no contar con fuentes de financiamiento disponibles, y si las hay su costo financiero es elevado considerando una economía dolarizada.

- La población económicamente activa, que ha visto disminuir fuentes de trabajo a raíz del cierre de empresas y sobre todo la llegada de trabajadores especialmente de Colombia y Perú, estimulada por salarios en dólares y las ventajas cambiarias que obtienen en sus países de origen.

A pesar de la crisis económica, Ecuador ha logrado mejoras significativas en las condiciones de vida de sus habitantes. A pesar de reducir la inflación al dolarizar, aun mantiene un alta inflación para la moneda dólar con un alto crecimiento en marzo de este ano que alcanzo el 4,23\% como se muestra en el cuadro a continuación:

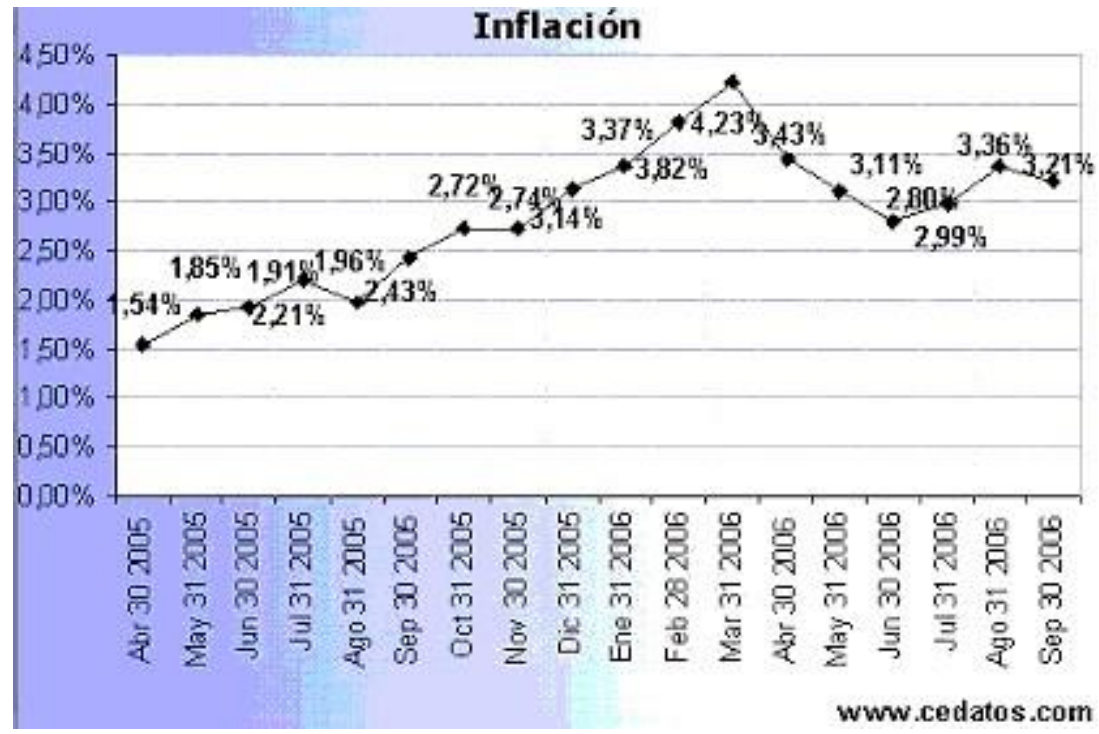

\section{Conclusiones.}

- Hemos analizado diversos factores componentes de la crisis económica que ya es una realidad en nuestro país, y en cada uno de estos, hemos hecho consideraciones de posibles alternativas para manejar de alguna manera los impactos que tienen en la economía. Sin embargo, debemos aceptar la realidad de que no estuvimos preparados para enfrentarla; en todos los ámbitos, el gobierno haciendo gastos que no fortalecieron más que el aparato burocrático; los empresarios al no tener un compromiso cívico con el país, el pueblo al no 
ahorrar en tiempos de bonanza para prevenir épocas difíciles, sumado a que nuestra economía se sustenta en pilares tan volátiles como el petróleo y las remesas.

- Es hora ya de cambiar la visión que tenemos de desarrollo, desarrollo no es dinero que viene de remesas y petróleo, el verdadero progreso camina de la mano del trabajo, del incentivo a la inversión, de creer en nuestra gente y apoyar sus ideas, de dejar de llenar los bolsillos de unas cuantas empresas transnacionales, de abandonar el camino de la corrupción, en definitiva de renovarnos como personas y como sociedad y empezar a arrimar el hombro en la reconstrucción de nuestra patria.

- El mundo entero exige más de nosotros, a fuerza tendremos que ser parte de la globalización para no sucumbir en el aislamiento; pero sobre todo, debemos pensar que las generaciones venideras nos juzgarán por lo que hicimos y por lo que dejamos de hacer, y es posible que para entonces ya no se cuente con el petróleo; por lo tanto, los jóvenes debemos cambiar ciertos conceptos y paradigmas propios de nuestro subdesarrollo.

\section{Referencias.}

Eduardo Cerdas, F. J. (2006). economia del ecuador 1999-2000. http://www.memoriacrisisbancaria.com/www/articulos/Crisis_Ecuador_19992000_Aula_Economia.pdf.

León, W. F. (1995-1996). crisis economica en el ecuador . ecuador.

Obando, I. A. (9 diciembre 2003). crisis del ecuador . ecuador : ISPN .

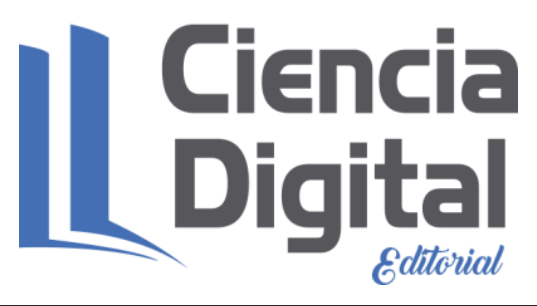




\section{Para citar el artículo indexado.}

Vera J. (2017). La crisis económica del Ecuador 1999-2000. Revista electrónica Visionario Digital 1(1), 5-20. Recuperado desde: http://cienciadigital.org/revistacienciadigital2/index.php/VisionarioDigital/article/view/254 1557

\section{Ciencia}

El artículo que se publica es de exclusiva responsabilidad de los autores y no necesariamente reflejan el pensamiento de la Revista Ciencia Digital.

El articulo queda en propiedad de la revista y, por tanto, su publicación parcial y/o total en otro medio tiene que ser autorizado por el director de la Revista Ciencia Digital. 